\title{
Steps to ensure adequate supply of biological medicines: considerations for the healthcare provider
}

\author{
Andrew Mica, MBA; Martha Mutomba, PhD; Larry Green, PharmD
}

\begin{abstract}
Introduction: When drug shortages occur, healthcare providers (HCPs) often must ration drugs, cancel or delay treatments, or utilize alternative drugs that may be less efficacious and/or are associated with increased risk of adverse outcomes, potentially impacting patient care. The likelihood of drug shortages may be increased for biological medicines, which are produced in living cells, require complex manufacturing processes and rigorous regulatory compliance, and are sensitive to storage and handling conditions. Most of the drugs currently in short supply are relatively inexpensive generic sterile injectables. As many suppliers of generic drugs may begin to produce biosimilars in the future, the issue of biological drug shortages may become an important consideration.

Discussion: This manuscript highlights critical supply chain parameters that HCPs should consider when evaluating a manufacturer's ability to maintain and deliver a continuous supply of biological medicines. Parameters to consider include: 1) effective management of drug inventory; 2 ) active management of raw material suppliers and supplies; 3 ) maintenance of multiple facilities to manufacture products; 4) establishment and effective management of robust and secure distribution networks; and 5) continuous improvement in processes and practices to anticipate events that may lead to disruptions in the drug supply chain.

Conclusion: Ensuring that approved biological medicines are available for adequate patient care through normal operations and during periods of supply shortages requires leveraging financial, technological and human resources. Proactive biological manufacturers invest in inventory and supply chain infrastructure to reduce the risk of drug shortages and shorten recovery times during a drug shortage, which should be a consideration by HCPs when making formulary decisions.
\end{abstract}

Keywords: Biological, drug shortage, healthcare provider, manufacturing, supply chain

\section{Background}

Shortages of essential drugs used in treatment, cure, or prevention of diseases have been reported globally in recent years [1-4]. In the US, drug shortages are routinely tracked by the US Food and Drug Administration (FDA) and the American Society of Health-System Pharmacists (ASHP) [3-6]. FDA tracks shortages of drugs that the agency considers medically necessary, i.e. drugs used to treat or prevent serious diseases or medical conditions for which there are no suitable drug substitutes to treat these conditions [4]. On the other hand, ASHP tracks shortages of all drugs [7]. Both FDA and ASHP have reported increasing trends in drug shortages. In 2010, FDA reported 178 drug shortages, and this number increased to 251 in 2011 [6, 8]. ASHP reported a total of 166 drug shortages in 2009, and this increased to 211 in 2010 $[4,8]$. Health Canada maintains a list of drugs in short supply through the Canadian Drug Shortage Database [9], and the shortage issue is growing as confirmed by a short survey conducted by the Canadian Medical Association in January 2011 [10]. Drug shortages have also been reported in a number of European countries including Germany, Hungary, Italy, The Netherlands, Spain and the UK $[1,11]$.

Most of the drugs in short supply are relatively inexpensive generic sterile injectables, including chemotherapy drugs, antibiotics, anaesthetics, blood-pressure lowering medications, and common electrolyte solutions and vitamins for patients receiving intravenous nutrition [6, 12-15]. A recent article by Woodcock and Wosinska [15] identified failure in quality management of manu- facturing facilities as the major driver behind most drug shortages, noting that $56 \%$ of sterile injectable drug shortages that occurred in 2011 are directly linked to quality manufacturing issues. Quality issues are also linked to downstream causal events such as plant shutdowns or manufacturing delays due to regulatory actions against a manufacturer for non-compliance to current Good Manufacturing Practice (cGMP) [4, 7, 15]. Also, product quality issues may lead to voluntary or regulatory-mandated product recalls $[7$, 16], that may potentially lead to drug shortages.

Manufacturing quality issues have also been linked to shortages of a number of biological medicines, which are complex drugs made from living organisms or their products. In 2009, one biological manufacturer announced the shutdown of a plant that produced three of its biological medicines due to the discovery of viral contamination in bioreactors at that plant [17]. As widely reported in the media and other outlets [17-20], that plant's shutdown led to shortages of two of the three affected drugs, impacting patient care. In another example, a general shortage of a biosimilar granulocyte colony-stimulating factor was reported in the UK in 2011, and this shortage continued in 2012 [1]. Additionally, shortages of a pegylated erythropoiesisstimulating agent were reported in Germany, Spain and the UK, starting in January 2012 [21-23].

\section{Impact of drug shortages}

In the context of drug shortages, healthcare providers (HCPs) face challenges in ensuring adequate supplies of essential drugs

Author for correspondence: Andrew Mica, MBA, Executive Director, Global Supply Chain, Amgen Inc, One Amgen Center Drive, MS 28-4-B, Thousand Oaks, CA 91320, USA

Submitted: 7 June 2013; Revised: 5 August 2013; Accepted: 7 August 2013; Published online first: 20 August 2013 
at all times. During a drug shortage, HCPs may need to consider rationing drugs, delaying or cancelling treatments, or utilizing alternative drugs that may be less efficacious and/or are associated with an increased risk of adverse outcomes [1-3, 13], potentially impacting adequate patient care. Additionally, the healthcare team will need to find alternative drug suppliers, which could result in administration of a more expensive product $[2-4,7,8,24]$. As a result, drug shortages can be time consuming and expensive to manage. According to a 2012 industry estimate [25], pharmacists spend an average of eight to nine hours a week addressing drug shortages, compared with only three hours a week in 2004. With respect to increased costs, a survey of US pharmacy directors indicated annual labour costs associated with managing drug shortages to be as high as US\$216 million [3, 25], with the increased burden falling mainly on pharmacists, but also impacting physicians, nurses, and pharmacy technicians.

In Europe, manufacturers are required to give two months notification to the European Medicines Agency (EMA) if supply of a product is temporarily or permanently interrupted [26]. In the US, the recently passed Prescription Drug User Fee Act (PDUFA) [27] includes a provision intended to address the drug shortage issue. Reforms in PDUFA require FDA to communicate drug shortages to the public through a drug shortages list, and also to expedite the approval of drugs in need. In addition, FDA released draft guidance [28] explaining the requirements for notifying the agency in the case of a planned discontinuation of certain drug products by manufacturers. FDA is also developing processes to assist with identification of alternative suppliers for drugs on the shortage list, including facilitation of temporary drug importation from manufacturers outside the US [6]. Although these measures may aid HCPs in managing shortages, they do not address many of the issues that may be associated with a manufacturer's inability to continuously supply essential biological drugs for adequate patient care. It is therefore important for HCPs to understand the complex processes involved in producing biologicals, and factors that are likely to lead to drug shortages.

\section{Drug supply considerations for biological medicines}

Currently more than 250 biological medicines have been approved to treat many serious illnesses, including cancer and inflammatory diseases [29]. Approximately $40 \%$ of pharmaceuticals in development are biologicals [30], therefore, the number of biological medicines approved to treat patients is expected to increase over the years. The number of biological medicines currently in short supply is much lower compared with that for generic drugs, however, the issue of biological drug shortages may become an important consideration in the future. Most of the drugs currently in short supply are relatively inexpensive generic sterile injectables, and as discussed earlier, the main driver behind these shortages is failure in quality management of manufacturing facilities by the suppliers. As many of the manufacturers supplying generic drugs begin to produce biosimilars, which are similar to but not identical to innovator biologicals, the issue of biological drug shortages may become an important consideration, given the complexity of the biological manufacturing process.

Unlike small molecule drugs that are produced using predictable chemical processes, that can be fully characterized, and are relatively stable [31, 32], biological drugs are produced and isolated from living cells, cannot be fully characterized, and are relatively sensitive to storage and handling conditions [31]. Production of biologicals requires specialized manufacturing facilities with precisely designed equipment for producing the desired product critical quality attributes under aseptic conditions to prevent microbial contamination. This requires highly trained and qualified staff as well as development of robust processes and quality control systems to ensure reproducible production of the same high quality product over the life cycle of the drug. Additionally, regulatory agencies like FDA conduct periodic inspections of both drug substance and final product manufacturing sites to evaluate compliance with cGMP. Manufacturers also have to distribute and store their products under controlled conditions to prevent loss of quality. Furthermore, as with generic injectables, almost all biologicals are administered parenterally from a sterile dosage form, and are thus susceptible to the same manufacturing quality issues that have impacted generic sterile injectables. Thus, manufacturing high quality biological drugs requires robust processes and facility design, rigorous regulatory compliance, and intricate supply chain distribution networks.

Of note, a single source manufacturer may be licensed to market a biological medicine for a particular indication with no alternative therapeutics. However, in some therapeutic areas, a number of biological medicines may be approved to treat the same indication, providing HCPs with alternative therapeutic options for their patients. An example is in inflammatory conditions such as rheumatoid arthritis where a number of biological modulators of the tumour necrosis factor pathway have been approved to treat this condition [33]. Additionally, with expiration of patents and exclusivity rights for some biologicals, biosimilars, are entering regulatory evaluation, approval, and marketing in different regions [34]. This presents HCPs with a choice between the approved innovator biological and one or more of the approved biosimilars. In these instances, HCPs may need to consider a variety of data and information beyond safety and efficacy in making formulary decisions. One such consideration is manufacturer attributes; more specifically, the manufacturer's ability to reliably maintain a continuous supply of a high quality biological medicine to ensure adequate patient care.

In the following sections, we highlight critical supply chain parameters that HCPs should consider when evaluating a manufacturer's ability to maintain and deliver a continuous supply of biological medicines. Key considerations for ensuring drug availability in the complex environment of manufacturing, regulatory compliance, and distribution challenges are outlined.

\section{Best practices for mitigating supply shortages of biological medicines}

Drug manufacturers may use various modalities to reduce the likelihood of a drug shortage or to shorten recovery time in the event of a drug shortage. These include: 1) effective management of drug inventory systems to minimize interruptions in drug supply; 2) effective management of raw material supplies and inventory to reduce interruptions to manufacturing operations due to shortages or poor quality raw materials; 3) maintenance of multiple facilities licensed to manufacture products to address extended interruptions at a primary 
manufacturing facility; 4) establishment and effective management of robust and secure distribution networks to ensure that products reach patients without interruption; and 5) continuous improvement in processes and practices to allow for a rapid response to events that may lead to potential disruptions in the drug supply chain.

\section{Effective management of drug inventory can be utilized to minimize interruptions in drug supply}

Inventory management is the process of overseeing the constant flow of inventory or units into and out of an existing inventory [35], and is a critical component of any drug supply chain risk mitigation strategy, especially during periods of high demand and/or production interruption. Inventory management is often measured using the inventory turnover ratio (inventory turn) [36]. Inventory turn is defined as the number of times inventory is sold and replaced over a period of time (such as a year) and is generally calculated as cost of goods sold divided by average inventory cost [36].

Typically, for non-pharmaceutical industries, a high inventory turn indicates greater sales efficiency and thus a low risk of monetary loss through stockpiling of unsold inventory [36]. However, for much of the pharmaceutical industry, a relatively low inventory turn is generally preferred, since it implies a large amount of stock on hand at any given time and therefore a decreased risk of drug shortages. Because of increasing economic pressures, some drug manufacturers may try to achieve operational efficiency by reducing drug manufacturing capacity and maintaining low drug inventories to reduce holding costs, as recently seen with sterile generic injectables [15]. If taken to excess, these efficiency measures could lead to additional constraints on the supply chain and increase the likelihood that a supply disruption will result in a drug shortage $[12,15]$, thus placing the maintenance of stable drug supplies for patient care at risk.

To assess the impact of inventory management on drug shortages in the US, we evaluated reported drug shortages and average inventory turns for seven major manufacturers, see Figure 1. Drug shortage data were as reported by ASHP over a one-year period, from January 2011 to January 2012 [5]. Average inventory turns over a five-year period (2006 to 2012) for the selected manufacturers were derived from financial information published in $10-\mathrm{K}$ reports for each of the companies. For each manufacturer, annual inventory turn was calculated as cost of sales divided by inventory for that year, and these data were used to calculate the five-year average (minimum, maximum) inventory turn. Of note, all manufacturers assessed in this evaluation produce and market both biological medicines and small molecule drugs. No shortages of biological medicines were reported in the US during the assessed time period, and therefore the shortages shown are for small molecule drugs. The two biotechnology manufacturers reported no shortages, the two large pharmaceutical manufacturers reported shortages of one and two drugs, respectively, and the three generics companies reported shortages of 5, 25, and 46 drugs, respectively, see Figure 1A. Of the seven major manufacturers, biotechnology manufacturers had low average inventory turns (1-1.5) and the large pharmaceutical manufacturers had slightly higher turns (1.5-2.0), see Figure 1B. Possibly related to the high number of
Figure 1: Reported drug shortages and inventory turns for seven major drug manufacturers

A

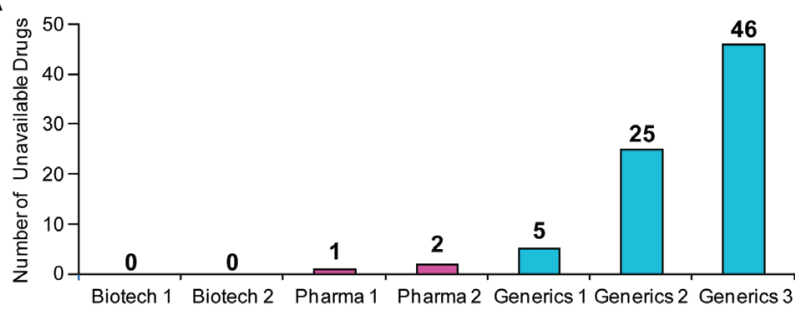

B

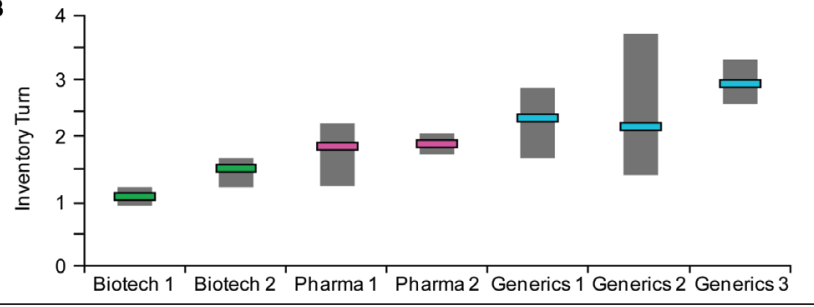

A) Drug shortages in US from January 2011 to January 2012 as reported by ASHP; [6] all the drugs in short supply in this study were generic injectables; B) Minimum, average, and maximum inventory turns for the period ranging from 2006 to 2010, calculated as cost of goods sold divided by average inventory value. Data are from public sources such as corporate websites and financial filings or from investment firm websites. Inventory turn is defined as the number of times inventory is sold and replaced over a period of time [10]. For this analysis, one inventory turn per year is equivalent to 12 months of average inventory onhand cumulative across all stages of manufacturing. Biotech: biotechnology manufacturer; Pharma: pharmaceutical manufacturer.

drug shortages, see Figure 1A, the three generics manufacturers showed higher inventory turns, averaging 2 to 4 turns a year, see Figure 1B.

The average inventory turn for each manufacturer is a surrogate measure of a manufacturer's inventory practices based on the manufacturer's product portfolio, and may not necessarily reflect the inventory management practices for a particular product of interest. A more detailed look at inventory practices for the product of interest may be more informative to HCPs. In the example provided earlier, where the discovery of viral contamination in bioreactors led to a plant closure [17], that manufacturer had existing inventory for two of the three impacted drugs; however, the company's stockpiles were not adequate to mitigate against the extended production loss that occurred, leading to the reported shortages of these two drugs. On the other hand, the manufacturer had an additional production facility for the third impacted product in this case, and therefore did not experience shortages of that particular product [17].

A closer review of practices by leading biological manufacturers indicates a multi-tiered approach to inventory management of individual products through control of cycle stock and safety stock, see Figure 2. In the context of product manufacturing, cycle stock is the portion of inventory that is depleted as orders are shipped and then replenished from the manufacturing floor or from suppliers during normal cycle times [37]. Operational safety stock is inventory carried to mitigate against shortage during periods of increased product demand (to cover variability in supply and demand) [37]. Appropriate inventory levels to maintain for both cycle and operational safety stock are determined through 
industry standard calculations, which consider manufacturing cycle times, forecasted patient demand, and a customer service multiplier [37]. An additional layer of strategic safety stock can be maintained to cover significant supply disruptions, such as shutdowns due to regulatory actions or natural disasters, quality defect-related quarantine of products, or product recalls. Strategic safety stock levels are applied after consideration of factors such as availability of multiple sources of raw materials and location of manufacturing facilities as well as historical experience with supply disruptions. Management of operational and strategic safety stock levels is applied at all stages of manufacturing in an effort to mitigate the risk of any single disruption in the supply chain. A related practice, in certain instances, is to hold such stock at separate geographic locations to mitigate interruptions in supply.

\section{Active management of raw materials is an important consideration for maintaining a stable drug supply}

Ensuring a continuous supply of high quality raw materials is another critical element in maintaining a stable drug supply. Raw materials used in manufacturing biologicals include biological and chemical source materials that are critical to the biosynthesis of the active pharmaceutical such as media ingredients required for cell growth, serum, growth factors, trypsin, and antibiotics, and also physical materials that are part of the finished products such as stoppers and vials $[38,39]$. Raw material contamination or compromise is a major safety concern in biological manufacturing and can adversely impact product quality. As such, raw material sourcing is rigorously regulated by agencies, including the FDA.

A high proportion (> 80\%) of pharmaceutical raw materials used by US manufacturers is sourced internationally, which can leave drug supply chains susceptible to issues with quality control, distribution, and national and local governmental interventions [40]. To mitigate against these risks, drug manufacturers need to actively manage their raw material supply and suppliers, see Figure 3. One aspect of raw material management is risk assessment based on characteristics of the supplier and the raw material itself as well as the impact of the raw material on the finished product, see Figure 3A. With regards to supplier risk, parameters assessed include the quality of the material produced by the supplier; the technical capabilities of the supplier; and the likelihood of the supplier to stay in business and continue to supply the required high quality raw material [38]. Material risk assessment includes intrinsic safety of the raw material, complexity of the raw material, and ease of handling. Intrinsic safety risk refers to the likelihood of the raw material being contaminated by the nature of its source [39]. As an

$\mathbf{B}$ example, raw materials that are sterilized may be considered safer and therefore less risky compared with raw materials that are not sterilized [39]. Finally, assessment of how the raw material impacts the production process itself is important in ensuring lot-to-lot consistency and therefore product quality. This includes an understanding of raw material attributes and knowing which attributes cause product variability, as well as how to manage those attributes to maintain required specifications in the final product [38].

Another aspect of raw material management is proactive preventative measures that a manufacturer can employ, see Figure 3B, including inventory management, supplier diversification, and application of enabling technologies. Similar to product management practices, raw material inventory management practices such as maintenance of appropriate levels of operational and strategic safety stock can be used to mitigate against drug shortages. With regards to diversification, where possible, raw materials are sourced from multiple suppliers and high-risk materials are stored in multiple geographic locations. Another consideration is the development of active business relationships with

An example of managing operational and strategic safety stock levels to mitigate drug shortage risk is shown. American Production and Inventory Control Society industry standard methodology [37] was used to calculate the appropriate level of operational safety stock using a $99.99 \%$ customer service level. Strategic safety stock levels are set based on the product supply risk assessment result (single vs dual-sourced and raw material supplier risks). ${ }^{a} \mathrm{Cycle}$ stock is the portion of inventory that is depleted as orders are shipped and then replenished from the manufacturing floor or from suppliers, and cover normal cycle times [37]. 'O Operational safety stock is the inventory that is carried to mitigate against product shortages during periods of increased product demand [37]. 'Strategic safety stock can be maintained to cover significant supply disruptions such as shutdowns due to regulatory actions or natural disasters, quality defect-related quarantine of products, or product recalls.

Figure 3: Active management of raw material supply and suppliers

\begin{tabular}{|} 
A Risk-Based Tools Used to Actively Manage Raw Material Supply and Suppliers \\
\hline Supplier Risk & \multicolumn{2}{|c|}{ Material Risk } & Process Impact \\
\hline Business Continuity & Material Safety & Quality \\
\hline Supplier Quality & Material Complexity & Process Performance \\
\hline Technical Capability & Handling & Facility Fit \\
\hline
\end{tabular}

\begin{tabular}{|c|c|c|c|}
\hline INVENTORY & DIVERSIFICATION & ITION & OLOGY \\
\hline $\begin{array}{l}\text { - Strategic safety } \\
\text { stock } \\
\text { - Order policies }\end{array}$ & $\begin{array}{l}\text { - Multiplesourcing } \\
\text { - Multiple supplier } \\
\text { sites }\end{array}$ & $\begin{array}{l}\text { - Supplier } \\
\text { qualifications } \\
\text { - Supplier auditing }\end{array}$ & $\begin{array}{l}\text { - Investment in } \\
\text { characterization } \\
\text { technology }\end{array}$ \\
\hline $\begin{array}{l}\text { - Supplier-managed } \\
\text { inventory }\end{array}$ & $\begin{array}{l}\text { - Multiple storage } \\
\text { locations }\end{array}$ & $\begin{array}{l}\text { - Supplier relationship } \\
\text { management }\end{array}$ & IS \\
\hline
\end{tabular}

A) Raw materials are assessed for risk to the supply chain based on characteristics of the supplier, intrinsic material risk, and impact to final product quality; B) Manufacturers can mitigate the risk of shortage by managing raw material inventories, diversification, prevention, and application of advanced technologies. 
suppliers, a practice that drug manufacturers are learning from the commodities industries. Thus, in addition to initial supplier qualification, monitoring of supply quality, and continuous supplier auditing, drug manufacturers also establish active communication channels with suppliers to ensure that information regarding quality and supply of critical raw materials is transparently shared between parties. Some manufacturers also invest in technology for characterizing raw materials. Technologies that may be useful in raw material characterization include the use of nuclear magnetic resonance testing to detect raw material adulteration and application of media treatment technology to prevent drug substance contamination [41-43]. These considerations require substantial investment and commitment of time and resources as well as an appropriate organizational infrastructure.

\section{Maintenance of multi-site manufacturing capabilities can address extended supply chain interruptions}

Similar to multiple sourcing strategies for raw materials, manufacturers can establish multiple facilities that are licensed to manufacture products [17]. This minimizes the risk of drug shortages due to interruption at the primary manufacturing facility, for example, related to interruptions caused by equipment failure, a regulatory action, or a natural disaster. Critical factors considered in making decisions to invest in multi-site manufacturing include geographic location of the primary site, complexity of the manufacturing process to produce the product, projected lead times to resolve typical manufacturing issues, and the potential effect on patient supply of an unexpected event. These assessments inform decisions regarding capital investment in additional internal manufacturing capabilities, submission of regulatory filings to allow manufacturing in new locations, reservation of back-up capacity with contract manufacturers, or rebalancing demand across existing sites to eliminate large concentrations of risk. Establishing and maintaining multi-site manufacturing capabilities ensures that, in the event of a shortage related to manufacturing site issues, production can resume elsewhere before existing inventory is depleted, providing a high level of protection from unexpected interruptions to drug supply. However, maintaining multiple manufacturing sites for a single product is expensive, and in the current cost-constrained environment, only a few manufacturers are likely to adopt this strategy.

\section{Establishment of robust and secure distribution networks can ensure that manufactured products reach patients} Drug manufacturers rely on extensive and complex distribution networks through distribution centres and wholesalers to deliver drugs from their manufacturing facilities to HCPs and patients, see Figure 4. Delay, diversion, or theft increases the risk of supply shortages. Most biological manufacturers are faced with an additional challenge of the need for temperaturecontrolled environments throughout the storage and transportation of their products to maintain product quality and integrity.
Biologicals manufacturers use different methods to mitigate distribution-related risks to supply. Products are mostly shipped directly from the manufacturer to hospitals, wholesalers, pharmacies, or physicians' clinics using controlled distribution channels and validated containers to ensure product quality, see Figure 4A. Where direct distribution is not logistically feasible or cost-effective, manufacturers use audited logistics service providers (LSPs) to extend their distribution networks. Logistics service providers are third party companies contracted to provide logistical support for distributing drug products from the manufacturer to the intended destinations. The support can include transportation, customs clearance, and storage of the drugs. To ensure adherence to internal standards, industry-leading companies train the LSP staff in appropriate product handling and security procedures.

As another protective layer, anti-theft and anti-counterfeiting measures are employed to prevent or mitigate the risk of product diversion or adulteration, see Figure 4B. These measures can include active tracking and monitoring of shipments through satellite networks, use of distribution channels that circumvent local and regional theft hotspots, and utilization of custom packaging materials that enable rapid identification of counterfeit or adulterated product. The use of unique identifiers such as bar codes and lot numbers on packaging may mitigate issues with counterfeit drugs, as this may assist with identification of the product at the site of patient administration. These measures are aimed at reducing the scope of an investigation or subsequent market recall, which can be critical in ensuring uninterrupted supply to patients.

\section{Rapid response to supply interruption signals may limit drug shortage risk}

Even the most robust supply management programmes do not eliminate the risk of a drug supply shortage. When these instances do arise - for example, in the case of a natural disaster such as a hurricane or an earthquake - it is critical that a manufacturer will have anticipated such events and is able to communicate supply and demand information quickly and seamlessly across global
Figure 4: Establishment of robust and secure distribution networks

A

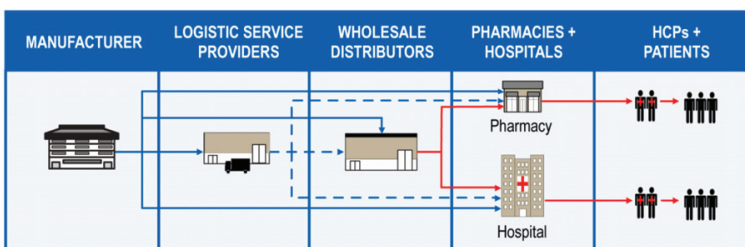

B

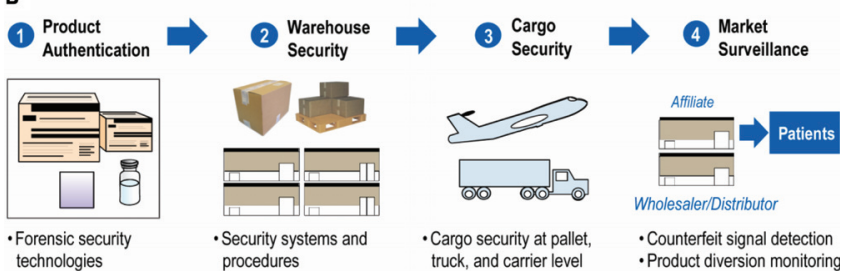

Establishment of robust and secure distribution networks can ensure that manufactured products reach patients; delay, diversion, or theft increases the risk of drug supply shortages: A) Direct distribution channels from the manufacturer to the hospitals, pharmacies, physician's clinics, and wholesalers using validated shipping containers ensure product quality and chain of custody; B) Logistics service providers can be used in situations where direct distribution from the manufacturer is not logistically feasible or cost-effective. HCPs: healthcare providers. 
manufacturing and distribution networks and to rapidly initiate processes to compensate for the reduction in drug supply that may occur, see Figure 5.

Typically, manufacturers rely on automated systems that couple customer ordering information with upstream supply plans and capabilities to ensure that production and shipping activities match customer needs. Some biological manufacturers have integrated these systems into their shopfloor manufacturing and quality assurance systems to synchronize plant and human resources across global networks. Enterprise integration can automatically and effectively manage most variability in supply and demand, even during a supply disruption. It should be recognized, however, that automated systems rely on a set of standard data for planning and managing supply. When information outside the standard data set is introduced into the system, the effectiveness of an automated system can be limited; this might occur when an unexpected and sudden event such as a natural disaster interrupts the process. Accordingly, some biological manufacturers have implemented manual, procedural-based, supply continuity plans that facilitate the flow of information in the event of an unexpected incident. These manual procedures define, in detail, the flow of communication and management decision-making to ensure that market conditions and supply information are well understood across the supply chain and that recovery plans appropriately prioritize the most critical supply requirements. As events unfold, management and teams can rely on these fail-safe processes to facilitate critical decisions quickly and effectively, mitigating the overall impact to patient care.

\section{Considerations for healthcare providers}

The anticipated increase in the number of biological medicines in the future will offer HCPs additional therapeutic options for treating patients. In cases where HCPs are faced with choices between biological medicines approved for the same indication, they may need to consider the manufacturer's ability to reliably maintain a continuous supply of high quality products for adequate patient care.

Safety and efficacy data have traditionally been the considered factors for making formulary decisions, and information on these parameters is usually available through a broad range of well-established sources, including the scientific literature. The information on drug supply parameters presented here has been historically difficult for HCPs to obtain and assess. However, increased attention to drug shortages is leading to a need for more transparency throughout the drug supply chain, potentially providing a competitive advantage to manufacturers that are transparent with respect to internal processes they employ to mitigate drug shortages.

HCPs should seek to understand a manufacturer's practices to mitigate against drug shortages. This may include understand- ing information regarding inventory management practices for individual products of interest, e.g. the amount of operational safety stock held to mitigate against periods of increased product demand and the amount of strategic safety stock held to mitigate against significant disruptions in drug supply. Equally important are the risk mitigation measures that a manufacturer employs to ensure adequate and high quality supply of raw materials, especially in the cases of single source raw material suppliers.

HCPs may also seek to assess and understand measures that manufactures take to ensure production of high quality drugs. These measures include investments in maintaining production facilities and equipment, conducting quality control testing and oversight, and developing processes for timely response to indicators of quality issues [15]. Quality-related information can be obtained from various sources. Companies sometimes issue press releases regarding drug recalls, anticipated drug shortages, or delays in product launches due to manufacturing quality issues. Also, FDA inspects manufacturing facilities to assess adherence to CGMP standards and publishes findings of noncompliance on its website $[15,44]$. An example of a regulatory publication found at the FDA's website is an FDA Form 483. This is a notification to the manufacturer of objectionable conditions identified during routine periodic compliance inspections of manufacturing facilities. For more significant violations or in cases where the manufacturer does not take corrective actions following a Form 483 notification, FDA may issue a 'Warning Letter' or take other enforcement actions, including revocation or suspension of the biologicals license [44]. The scope and severity of these regulatory actions may be important for HCPs to consider when assessing a manufacturer's reliability history. As indicated by Woodcock and Wosinska in reference to sterile injectable drugs [15], FDA could consider providing meaningful manufacturing metrics regarding product quality to assist HCPs when making formulary decisions.

Additionally, manufacturer customer service representatives can assist HCPs in understanding product security features and policies and practices regarding distribution management. 
Manufacturers may also consider preparing overviews of continuity plans to be followed in case of an interruption in production of its drugs, and share these plans with HCPs. This might promote increased transparency amongst stakeholders who are likely to be impacted by an interruption in the drug supply chain.

Another consideration is for HCPs to include assessment of the manufacturer attributes discussed here as part of a formulary checklist. Table 1 provides a checklist of manufacturer attributes to consider.

\section{Table 1: Manufacturer attributes to consider when evaluating} biological medicines for formulary inclusion

\begin{tabular}{|c|c|}
\hline Attribute & Factors to consider \\
\hline $\begin{array}{l}\text { Medication } \\
\text { availability [45] }\end{array}$ & $\begin{array}{l}\text { - Does the manufacturer foster confidence } \\
\text { in the uninterrupted supply of the } \\
\text { product? } \\
\text { - Does the manufacturer maintain } \\
\text { adequate production and stock to } \\
\text { support expected demand and to } \\
\text { protect against shortages associated } \\
\text { with potential production disruptions? } \\
\text { - Does the manufacturer maintain } \\
\text { additional operational safety stock } \\
\text { and/or strategic safety stock? } \\
\text { - Does the manufacturer maintain } \\
\text { more than one manufacturing site } \\
\text { or have access to back-up facilities } \\
\text { to manufacture the product in the } \\
\text { case of an extended production } \\
\text { interruption at the primary facility? }\end{array}$ \\
\hline $\begin{array}{l}\text { History of } \\
\text { shortages and } \\
\text { recalls }[45]\end{array}$ & $\begin{array}{l}\text { - Has the manufacturer experienced } \\
\text { shortages of this product or other } \\
\text { products? } \\
\text { - If so, what was the cause and how } \\
\text { often has the manufacturer experi- } \\
\text { enced such shortages? } \\
\text { - Has the product ever been recalled } \\
\text { because of quality concerns? } \\
\text { - Has the manufacturer had other products } \\
\text { recalled as a result of quality concerns? }\end{array}$ \\
\hline $\begin{array}{l}\text { Safe handling } \\
\text { management and } \\
\text { administration } \\
{[45]}\end{array}$ & $\begin{array}{l}\text { - Does the manufacturer adequately } \\
\text { maintain and document controlled } \\
\text { temperature, e.g. 'cold chain', } \\
\text { distribution for the product? }\end{array}$ \\
\hline $\begin{array}{l}\text { Supply chain } \\
\text { security }\end{array}$ & $\begin{array}{l}\text { - What system/packaging characteristics } \\
\text { provide anti-counterfeit protection? } \\
\text { - Do these characteristics provide a } \\
\text { high or low level of protection? } \\
\text { - Does the manufacturer maintain robust } \\
\text { market surveillance to detect potential } \\
\text { counterfeits? }\end{array}$ \\
\hline $\begin{array}{l}\text { Processes and } \\
\text { procedures }\end{array}$ & $\begin{array}{l}\text { - Does the manufacturer maintain/share } \\
\text { overviews of continuity plans followed } \\
\text { in the case of a drug supply interruption } \\
\text { such as an interruption caused by a } \\
\text { natural disaster? }\end{array}$ \\
\hline
\end{tabular}

\section{Conclusion}

The recent increase in drug shortages highlights the importance of ensuring that patients receive the medicines they require at all times. Maintaining a continuous supply of approved biological medicines through normal operations and during periods of supply shortages requires leveraging financial, technological and human resources. Proactive drug manufacturers heavily invest in inventory and supply chain infrastructure to reduce the risk of drug shortages and to shorten recovery times in the event of a drug shortage. Therefore, when making formulary decisions, HCPs need to understand and consider critical supply chain parameters that can impact a manufacturer's ability to maintain a reliable supply of drugs for their patients. To aid in formulary decision making, manufacturers and regulators should consider the value of making such information available. This will become increasingly important as the number of marketed biologicals and the number of suppliers increase.

\section{Funding sources}

This work was funded by Amgen Inc.

Competing interests: Mr Andrew Mica, Dr Martha Mutomba, and Dr Larry Green are employees of Amgen Inc and own stock in Amgen Inc.

Provenance and peer review: Not commissioned; externally peer reviewed.

\section{References}

1. GaBI Online - Generics and Biosimilars Initiative. Biosimilars and cancer drug shortages in Europe [www.gabionline.net]. Mol, Belgium: Pro Pharma Communications International; [cited 2013 Aug 5]. Available from: www.gabionline. net/Pharma-News/Biosimilars-and-cancer-drug-shortages-in-Europe

2. Gatesman ML, Smith TJ. The shortage of essential chemotherapy drugs in the United States. N Engl J Med. 2011;365(18):1653-5.

3. Kaakeh R, Sweet BV, Reilly C, et al. Impact of drug shortages on U.S. health systems. Am J Health Syst Pharm. 2011;68(19):1811-9.

4. Ventola CL. The drug shortage crisis in the United States: causes, impact, and management strategies. P T. 2011;36(11):740-57.

5. American Society of Health-System Pharmacists.Drug shortages: current drugs [homepage on the Internet]. [cited 2013 Aug 5]. Available from: http://www. ashp.org/DrugShortages/Current

6. US Food and Drug Administration. US. Department of Health and Human Services. Frequently asked questions about drug shortages [homepage on the Internet]. 2013 [cited 2013 Aug 5]. Available from: http://www.fda.gov/Drugs/ DrugSafety/DrugShortages/ucm050796.htm\#q1

7. ASHP Expert Panel on Drug Product Shortages; Fox ER, Birt A, James KB, Kokko H, Salverson S, Soflin DL. ASHP guidelines on managing drug product shortages in hospitals and health systems. Am J Health Syst Pharm. 2009;66(15):1399-406.

8. Shortages of cancer drugs in the USA. Lancet Oncol. 2011;12(4):313.

9. Canadian Drug Shortage Database. Drug shortages [homepage on the Internet]. 2013 [cited 2013 Aug 5]. Available from: http://drugshortages.ca/drugshortages.asp

10. Canadian Medical Association. e-Panel survey summary: generic prescription drug shortages [homepage on the Internet]. 2013 [cited 2013 Aug 5]. Available from: http://www.cma.ca/advocacy/generic-prescription-drug-shortages

11. Tirelli U, Berretta M, Spina M, Michieli M, Lazzarini R. Oncologic drug shortages also in Italy. Eur Rev Med Pharmacol Sci. 2012;16(1):138-9.

12. US Food and Drug Administration. US. Department of Health and Human Services. A review of FDA's approach to medical product shortages [homepage 
on the Internet]. 2011 [cited 2013 Aug 5]. Available from: http://www.fda.gov/ downloads/AboutFDA/ReportsManualsForms/Reports/UCM277755.pdf

13. Chabner BA. Drug shortages - a critical challenge for the generic-drug market. N Engl J Med. 2011;365(23):2147-9.

14. Kaiser J. Medicine. Shortages of cancer drugs put patients, trials at risk. Science. 2011;332(6029):523.

15. Woodcock J, Wosinska M. Economic and technological drivers of generic sterile injectable drug shortages. Clin Pharmacol Ther. 2013;93(2):170-6.

16. Thompson CA. Stakeholders in supply chain discuss shortages. Am J Health Syst Pharm. 2011;68(1):9-10.

17. Tomlin B, Wang Y. Operational strategies for managing supply chain disruption risk. In: Kouvelis P, Boyabatli O, Dong L, Li R, editors. The handbook of integrated risk management in global supply chains. John Wiley \& Sons, Inc.; 2011. p. 79-101.

18. Wallack T. Genzyme expects lingering drug shortage, $\$ 175 \mathrm{~m}$ fine. The Boston Globe [newspaper on the Internet]. 2010 Apr 22 [cited 2013 Aug 5]. Available from: http://www.boston.com/business/healthcare/articles/2010/04/22/ genzyme_expects_lingering_drug_shortage_175 m_fine

19. Pollack A. Genzyme drug shortage leaves users feeling betrayed. The New York Times [newspaper on the Internet]. 2010 Apr 15 [cited 2013 Aug 5]. Available from: http://www.nytimes.com/2010/04/16/business/16 genzyme.html?page wanted=all\&_r $=0$

20. Gever J. End near for Fabry drug shortage. Medpage Today. 2012 Jan 24 [cited 2013 Aug 5]. Available from: http://www.medpagetoday.com/ProductAlert/ Prescriptions/30816

21. Bundesinstitut fur Arzneimittel und Medizinprodukte. Important information for professional circles on the possible supply shortage of Mircera $100 \mathrm{mcg}$ (methoxy polyethylene glycol-epoetin beta) - suggestion for a switch to alternative treatments [homepage on the Internet]. 2012 [cited 2013 Aug 5]. Available from: http://www.bfarm.de/EN/vigilance/riskinfo/2012/info-mircera2

22. Pharmaceutical Research and Manufacturers of America. Medicines in Development. Biotechnology 2011 Report [homepage on the Internet]. 2013 [cited 2013 Aug 5]. Available from: http://www.phrma.org/sites/default/files/1776/biotech2011.pdf

23. GaBI Online - Generics and Biosimilars Initiative. Roche encounters manufacturing issues with epoetin-beta [www.gabionline.net]. Mol, Belgium: Pro Pharma Communications International; [cited 2013 Aug 5]. Available from: http://www. gabionline.net/Biosimilars/News/Roche-encounters-manufacturing-issues-withepoetin-beta

24. Hadjinicolaou AV, Nisar MK, Bhagat S, Parfrey H, Chilvers ER, Ostör AJ. Noninfectious pulmonary complications of newer biological agents for rheumatic diseases - a systematic literature review. Rheumatology (Oxford). 2011;50(12): 2297-305.

25. Hill J, Reilly C. Can the United States ensure an adequate supply of critical medications? The Food and Drug Law Institute's Food and Drug Policy Forum. Food and Drug Law Institute. 2011;1(16):1-14. Available from: http://www. ashp.org/doclibrary/policy/drugshortages/fdli-article-on-drug-shortages.aspx

26. European Commission. European Medicines Authority. Directive 2001/83/EC of the European Parliament and of the Council of 6 November 2001 on the Community code relating to medicinal products for human use (OJ L 311, 28.11.2001, p. 67) [homepage on the Internet]. 2001 [cited 2013 Aug 5]. Available from: http:// eur-lex.europa.eu/LexUriServ/LexUriServ.do?uri=OJ:L:2001:311:0067:0128:en:PDF

27. US Government Printing Office. Food and Drug Administration Safety and Innovation Act (FDASIA); Title X - Drug Shortages. S. 3187 [homepage on the
Internet]. 2012 [cited 2013 Aug 5]. Available from: http://www.gpo.gov/fdsys/ pkg/PLAW-112publ144/pdf/PLAW-112publ144.pdf

28. US Food and Drug Administration. US. Department of Health and Human Services. Guidance for Industry: Notification to FDA of issues that may result in a prescription drug or biological product shortage. Draft Guidance [homepage on the Internet]. 2012 [cited 2013 Aug 5]. Available from: http://www.fda.gov/ downloads/Drugs/GuidanceComplianceRegulatoryInformation/Guidances/ UCM292426.pdf

29. Biotechnology Industry Organization. What is biotechnology [homepage on the Internet]? 2013 [cited 2013 Aug 5]. Available from: http://www.bio.org/node/517

30. Langer E. A decade of biomanufacturing: shifts toward process improvement reveal industry maturity. BioProcess International. 2012;10(S6):65-8.

31. Genazzani AA, Biggio G, Caputi AP, et al. Biosimilar drugs: concerns and opportunities. BioDrugs. 2007;21(6):351-6.

32. Gottlieb S. Biosimilars: policy, clinical, and regulatory considerations. Am J Health Syst Pharm. 2008;65(14 Suppl 6):S2-8.

33. Miller AV, Ranatunga SK. Immunotherapies in rheumatologic disorders. Med Clin North Am. 2012;96(3):475-96.

34. Lee JF, Litten JB, Grampp G. Comparability and biosimilarity: considerations for the healthcare provider. Curr Med Res Opin. 2012;28(6):1053-8.

35. BarcodesInc. What is inventory management? [homepage on the Internet]. 2013 [cited 2013 Aug 5]. Available from: http://www.barcodesinc.com/ articles/what-is-inventory-mangement.htm

36. Accounting for Management. Inventory turnover ratio or stock turnover ratio (ITR). 2013 [cited 2013 Aug 5]. Available from: http://www.accountingformanagement.com/stock_turn_over_ratio.htm\#Definition

37. King PL. Crack the code: understanding safety stock and mastering its equations. APICS magazine. 2011;21(4):33-36.

38. Beck B, Schenerman M, Dougherty J, et al. Raw material control strategies for bioprocesses. BioProcess International. 2009;18-33.

39. Khan AS. Regulatory considerations for raw materials used in biological products. PDA J Pharm Sci Technol. 2010;64(5)451-7.

40. Premier. Hospital drug shortages [homepage on the Internet]. 2011 [cited 2013 Aug 5]. Available from: http://www.premierinc.com/about/advocacy/ issues/11/Hospital-Drug-Shortages-Premier-Policy-Paper.pdf

41. Kirdar AO, Chen G, Weidner J, Rathore AS. Application of near-infrared (NIR) spectroscopy for screening of raw materials used in the cell culture medium for the production of a recombinant therapeutic protein. Biotechnol Prog. 2010; 26(2):527-31.

42. Rathore AS, Low D. Managing raw materials in the QbD paradigm, part 1: understanding risks. BioPharm Int. 2010;23(1):34-40.

43. Rathore AS, Low D. Managing raw materials in the QbD paradigm, part 2: Risk Assessment and Communication. BioPharm Int. 2010;48-57.

44. US Food and Drug Administration. U.S. Department of Health and Human Services. Inspections, compliance, enforcement, and criminal investigations [homepage on the Internet]. 2013 [cited 2013 Aug 5]. Available from: http:// www.fda.gov/ICECI/default.htm

45. Krämer I, Tredree R, Vulto AG. Points to consider in the evaluation of biopharmaceuticals. In: Schellekens H, Vulto AG, editors. Biopharmaceuticals for European Hospital Pharmacists. Mol: PPME; 2008. p. 48-56.

DOI: 10.5639/gabij.2013.0203.038

Copyright $\odot 2013$ Pro Pharma Communications International 